\title{
Relationship between Systolic Time Intervals and Heart Rate during Atrial or Ventricular Pacing in Normal Subjects
}

\author{
Giuseppe Ferro, M.D., Bruno Ricciardelli, M.D., Luigi SaccÁ, M.D., \\ Massimo Ghiariello, M.D., Massimo Volpe, M.D., \\ Michele G. Tari, M.D., and Bruno Trimarco, M.D.
}

\begin{abstract}
SUMmary
Systolic time intervals (STI) are regarded as good indices of cardiac performance in many heart diseases. It must be considered, however, that they are temporally related to the cardiac contraction cycle and, therefore, may be modified by heart rate changes. Thus, it is necessary to define the possible relationship between STI and heart rate changes. In this study, changes in heart rate were induced by atrial and ventricular pacing. Tachycardia caused a proportional decrease of left ventricular ejection time (LVET) $(y=275.142-1.0025 x, r=0.76, p<0.001$ for atrial pacing and $y=298.28-0.691 \mathrm{x}, \mathrm{r}=-0.75, \mathrm{p}<0.001$ for ventricular pacing, respectively), but did not modify the pre-ejection period (PEP) and the isometric contraction time (ICT) and the electromechanical interval $\left(\mathrm{QS}_{1}\right)$.

These results demonstrate that while LVET must be corrected for the changes in heart rate, no correction of PEP and ICT is necessary.
\end{abstract}

\section{Additional Indexing Words :}

Heart performance Polygraphic tracings

Atrial contribution to systole

GYSTOLIG time intervals (STI), defined many years ago, ${ }^{1-3}$ ) have re$D$ ceived new attention over the past few years for the correlations which have been made with more direct parameters of myocardial performance. ${ }^{4)-10}$ ) STI are temporally related to the cardiac contraction cycle and, therefore, it would be important to ascertain the relationship, if any, between STI and heart rate. Actually, it has been demonstrated that there is an inverse relationship, both at rest and during atrial pacing, between left ventricular ejection time (LVET), which is strictly correlated to the stroke volume, and heart rate. ${ }^{9 / 11)}$ On the contrary the influence of heart rate on pre-ejection period (PEP) and on isometric contraction time (ICT) is not completely

From the Istituto di Patologia Speciale Medica e Metodologia Clinica, 2 Facoltà di Medicina e Chirurgia, Università di Napoli, Via S. Pansini 5-80131, Napoli, Italy.

This work was supported by C.N.R. (grant $\mathrm{n}^{\circ} 7300505.04$ ).

Received for publication January 9, 1980. 
understood. In fact, some investigators support the hypothesis that, at rest, PEP changes when heart rate varies, because it is affected by the autonomic nervous activity. ${ }^{5)}$ Moreover, Wiggers ${ }^{21}$ in the dog and Orenskov ${ }^{12}$ ) in man demonstrated that heart rate increments induce significant decrease of ICT, while, on the contrary, Harris et al ${ }^{13}$ ) failed to observe any significant change in ICT in 3 normal subjects during atrial pacing.

This study was undertaken in order to define the relationship between STI and heart rate during tachycardia induced by atrial and ventricular pacing that causes well known hemodynamic changes. ${ }^{14-20)}$

\section{Methods}

The study was performed in 21 normal subjects of either sex, whose age ranged from 20 to 50 years. Twelve were studied during atrial pacing and the remaining during ventricular pacing. The studies were performed in the postabsorptive state after a $12-14 \mathrm{hr}$ fast. Right heart catheterization was performed with a $\mathrm{n}^{\circ} 5 \mathrm{~F}$ bipolar electrode catheter, inserted percutaneously into a brachial vein and then positioned at the lateral wall of the right atrium or ventricle for atrial and ventricular pacing, respectively. A photographic multichannel polygraph (Electronics for Medicine DR8) was used to record simultaneously ECG, phonocardiogram, and carotid arterial pulse tracing at a paper speed of $100 \mathrm{~mm} / \mathrm{sec}$, while the subject was lying on an examination bed in the supine position. The mean values of 5 cardiac cycles were evaluated for the following parameters:

- Icft ventricular ejection time (LVET), measured from the beginning of the upstroke to the onset of the dicrotic notch of the carotid pulse;

-electromechanical systole $\left(\mathrm{QS}_{2}\right)$, recorded as the interval from the onset of QRS complex to the first high frequency vibration of the second heart sound;

- pre-ejection period (PEP), calculated by subtracting the ejection time from the electromechanical systole $\left(\mathrm{QS}_{2}-\mathrm{LVET}\right)$;

-isovolumetric contraction time (ICT), obtained by subtracting the electromechanical interval from PEP (PEP-QS $\left.{ }_{1}\right)$;

-electromechanical interval $\left(\mathrm{QS}_{1}\right)$, measured from the onset of the QRS complex in the ECG to the onset of ventricular contraction;

-PEP/LVET ratio.

All these parameters were first recorded at rest. Then, heart rate was gradually increased by atrial or ventricular pacing starting from a rate of 5-10 beats/ min above the resting level. Lead II of ECG was continuously monitored. Subsequent rate increases were in increments of approximately 20 beats/min until the rate of 150 beats $/ \mathrm{min}$ was reached. STI were recorded $2 \mathrm{~min}$ after each increment,

Data were presented as mean $\pm 1 \mathrm{SE}$. Statistical analysis was performed by the Student's $t$ test for unpaired samples and by the regression analysis.

\section{Results}

The basal mean values of STI in the group of subjects who underwent 
the atrial pacing were not statistically different from those obtained in the group in which ventricular pacing was performed (Table I).

During atrial and ventricular pacing, LVET showed an inverse correlation with heart rate $(y=275.14-1.0025 x, r=-.76, p<0.001$ for atrial pacing and $y=298.28-0.691 x, r=-.75, p<0.001$ for ventricular pacing). These 2 regression equations were significantly different with regard to both the slope $(\mathrm{p}<0.001)$ and the intercept $(\mathrm{p}<0.005)$ (Fig. 1).

No relationship was found between heart rate and PEP, ICT, and $\mathrm{QS}_{\perp}$ during both types of electrostimulations. These parameters did not show any statistically significant change from the rest value during atrial pacing. In contrast, during ventricular pacing, PEP and $\mathrm{QS}_{1}$ increased soon after the beginning of electrostimulation from the basal values of $98.3 \pm 4.5$ and $65.5 \pm 4.2 \mathrm{msec}$, respectively, to $151.1 \pm 4.1$ and $118.3 \pm 3.3 \mathrm{msec}$. Then, no change in PEP and $\mathrm{QS}_{1}$ was observed with further increments of heart rate.

Table I. Basal Values of Heart Rate and STI of the Subjects Who Underwent Atrial Pacing (Group 1) and Ventricular Pacing

\begin{tabular}{l|cccccc}
\hline & $\begin{array}{c}\text { H.R. } \\
(\text { beats/min })\end{array}$ & $\begin{array}{c}\text { LVET } \\
(\mathrm{msec})\end{array}$ & $\begin{array}{c}\text { PEP } \\
(\mathrm{msec})\end{array}$ & $\begin{array}{c}\text { ICT } \\
(\mathrm{msec})\end{array}$ & $\begin{array}{c}\mathrm{QS}_{1} \\
(\mathrm{msec})\end{array}$ & PEP/LVET \\
\hline Group 1 $(\mathrm{n}=12)$ & $78.4 \pm 4.5$ & $297.9 \pm 6.7$ & $97.6 \pm 3.2$ & $36 \pm 1.8$ & $60 \pm 2.3$ & $0.328 \pm 0.013$ \\
Group 2 $(\mathrm{n}=9)$ & $72.1 \pm 5.4$ & $291.1 \pm 8.4$ & $98.3 \pm 4.5$ & $33.8 \pm 2$ & $65.5 \pm 4.2$ & $0.314 \pm 0.018$ \\
& n.s. & n.s. & n.s. & n.s. & n.s. & n.s.
\end{tabular}

Each value represents mean \pm SE. Statistical comparison has been performed between corresponding values of the 2 groups using $t$ test for unpaired observations. $n=$ number of subjects.

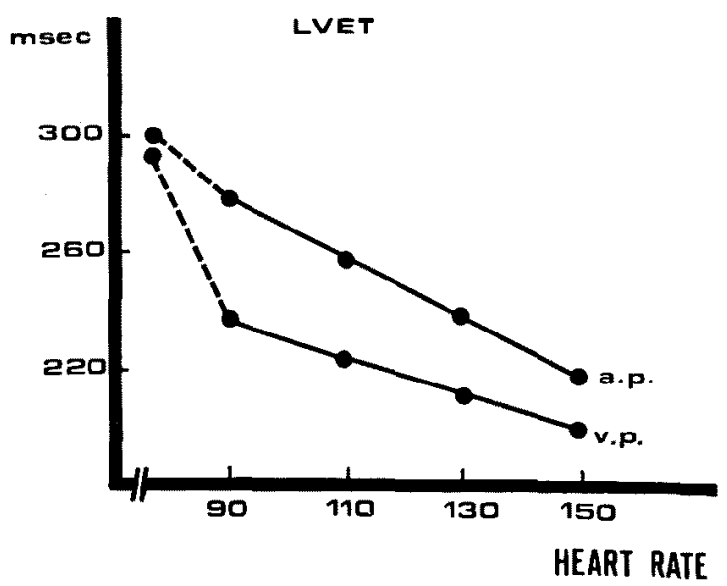

Fig. 1. Relationship between heart rate and LVET during atrial pacing (a.p., $\mathrm{n}=12$ ) and ventricular pacing (v.p., $\mathrm{n}=9$ ). Each point represents mean. Dashed lines represent the period before the beginning of the electrostimulation. 


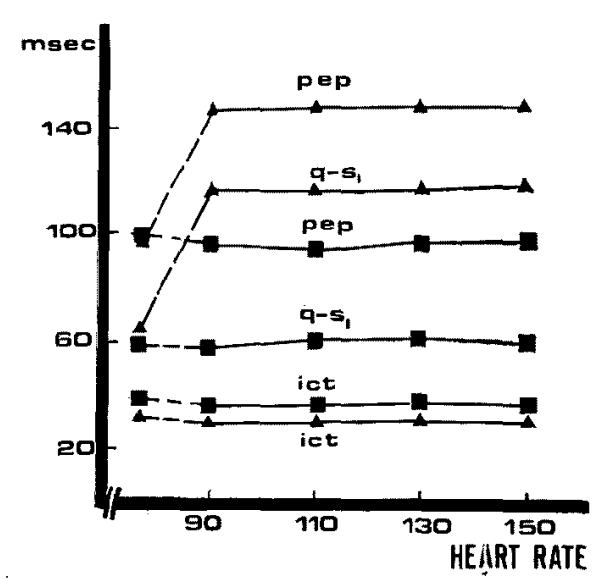

Fig. 2. Relationship between PEP, $\mathrm{QS}_{1}, \mathrm{ICT}$, and heart rate during atrial pacing ( $-\mathbf{-})(n=12)$ and ventricular pacing $(\boldsymbol{\Delta}-\mathbf{\Delta})(n=9)$. Each point represents mean. Symbols as in Fig. 1.

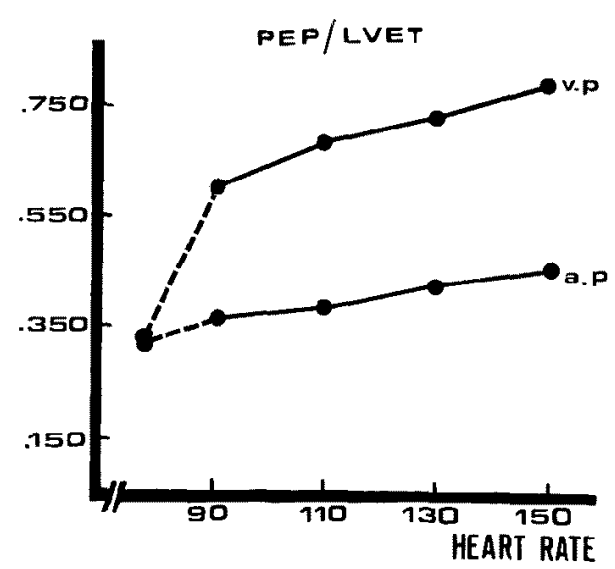

Fig. 3. Relationship between PEP/LVET ratio and heart rate during atrial pacing (a.p) $(n=12)$ and ventricular pacing (v.p) $(n=9)$. Each point represents mean. Symbols as in Fig. 1.

Furthermore, ICT was not modified by ventricular pacing (Fig. 2).

Finally, the PEP/LVET ratio showed a direct correlation with heart rate during both types of electrostimulations $(y=0.20+0.001 x, p<0.001$ for atrial pacing; $\mathrm{y}=0.43+0.002 \mathrm{x}, \mathrm{p}<0.001$ for ventricular pacing). These 2 regression equations were different with regard to both the slope $(p<0.01)$ and the intercept $(\mathrm{p}<0.001)$ (Fig. 3).

\section{DisGussion}

The absence of statistically significant differences in the rest values of STI between the subjects studied with atrial pacing and those in whom ventri- 
cular pacing was performed insures that the changes in STI following pacing are exclusively due to the 2 different ways of cardiac electrostimulation.

LVET, an index strictly related to stroke volume, shows during atrial and ventricular pacing a linear inverse correlation with heart rate, in agreement with the hemodynamic finding that stroke volume progressively decreases when heart rate increases.

The highly significant difference between the 2 LVET regression equations obtained during atrial and ventricular pacing, respectively, could probably mean that the stroke volume during ventricular pacing is smaller than during atrial pacing because in the former the hemodynamic contribution of the atrial systole to the ventricular filling, and then to the stroke volume, is minimal. This observation tends to support the hypothesis that the contribution of the atrial systole to the cardiac function is not negligible according to the reports of previous authors. ${ }^{21,22}$ ) Moreover, the finding that during atrial pacing at high heart rate LVET tends to approach the values obtained during ventricular pacing suggests that the effectiveness of the atrial contribution decreases as heart rate increases, thus confirming the hypothesis of Benchimol et $\mathrm{al}^{21)}$ that a properly timed atrial systole improves cardiac function significantly.

It is of interest in the current study that $\mathrm{QS}_{1}, \mathrm{PEP}$, and ICT do not show any relationship with heart rate because they are not modified during the 2 types of cardiac stimulation. In fact, the initial increments of $\mathrm{QS}_{1}$ and PEP during ventricular pacing are probably due to the ventricular anomalous depolarization produced by this way of electrostimulation. ${ }^{23)}$ Such a behaviour of PEP and ICT during pacing-induced tachycardia suggests that these parameters are not affected by heart rate changes. On the other hand, this conclusion seems to be in contrast with the common opinion that PEP and ICT are reliable indices of myocardial contractility, by virtue of the close correlation found between these 2 parameters and the invasive indices of the left ventricular performance. ${ }^{10}$ In fact, it has been demonstrated in normal subjects and in isolated myocardial tissue that the pacing-induced increment in heart rate produces an increase of $V \max$ and $\mathrm{dp} / \mathrm{dt} \max .{ }^{18), 24}$, This contrast, however, may be explained by the fact that PEP and ICT are influenced by the myocardial contractility itself (as expressed by the Vmax and the $\mathrm{dp} / \mathrm{dt} \max$ ) as well as by the ventricular end-diastolic pressure (preload) and the aortic diastolic pressure (after-load). In other words, PEP and ICT can be considered as a cathetus of a right angled triangle in which the hypotenuse is the $\mathrm{dp} / \mathrm{dt}$ and the other cathetus the difference between aortic diastolic pressure and ventricular end-diastolic pressure, according to Metzger's hypothesis." Therefore, one can easily understand that PEP and 
ICT may not vary if the increment of the $\mathrm{dp} / \mathrm{dt}$ is associated with a decrement of ventricular end-diastolic pressure as it occurs during cardiac pacing.

Finally, the PEP/LVET ratio reflects essentially, during atrial and ventricular pacing, the LVET behaviour, since PEP does not vary with heart rate increments.

In conclusion, this study confirms that pacing-induced tachycardia causes a progressive reduction in LVET, so that it is necessary to correct LVET for heart rate. On the contrary, PEP and ICT are not modified by heart rate changes probably because they are not indices of myocardial contractility sensu strictu, but they also depend on other parameters such as ventricular end-diastolic pressure and aortic diastolic pressure.

\section{REFERENCES}

1. Wiggers GJ: Studies on the consecutive phases of the cardiac cycle. The duration of the consecutive phases of the cardiac cycle and the criteria for their precise determination. Am J Physiol 56: 415, 1921

2. Wiggers GJ: Studies on the consecutive phases of the cardiac cycle II. The laws governing relative duration of ventricular systole and diastole. Am J Physiol 56: 439, 1921

3. Lombard WP, Cope OM: The duration of systole and left ventricle in man. Am. J Physiol 77: 263,1926

4. Weissler AM, Peeler RC, Rochill WH Jr: Relationship between left ventricular ejection time, stroke volume and heart rate in normal individuals and patients with cardiovascular diseases. Am Heart J 62: 367, 1961

5. Weissler AM, Harris WS, Schoenfield CD: Systolic time intervals in heart failure in man. Circulation 37: 149, 1968

6. Weissler AM, Harris WS, Schoenfield CD: Bedside techniques for the evaluation of ventricular function in man. Am J Cardiol 23: 577, 1969

7. Metzger CC, Choug CB, Kroetz FW, Leonard JJ: True isovolumetric contraction time: its correlation with two external indices of ventricular performance. Am J Cardiol 25: 434, 1970

8. Martin GD, Shaver JA, Thompson ME, Sudhakar-Readdy P, Leonard JJ: Direct correlation of external systolic time intervals with internal indices of left ventricular function in man. Circulation 44: 419, 1971

9. Garrad CL Jr. Weissler AM, Dodge HT: The relationship of alterations in systolic time intervals to ejection fraction in patients with cardiac disease. Circulation 42: 455, 1970

10. Ahmed SS, Levinson GE, Schwartz GJ, Ettinger PO: Systolic time intervals as measures of the contractile state of the left ventricular myocardium in man. Circulation 36: 559, 1970

11. Braunwald E, Sarneff SJ, Stainsby WN: Duration and mean rate of ventricular ejection. Circulat Res 6: 319, 1958

12. Orenskov $\mathrm{C}$ : Indirect measurement of isovolumetric contraction time on the basis of polygraphic tracing. Cardiologia 47:315, 1965

13. Harris WS, Schoenfield CD, Weissler AM: Effects of adrenergic receptors activation and blockade on the systolic pre-ejection period, heart rate and arterial pressure in man. J Clin Invest 46: 1704, 1967

14. Benchimol A, Ligget MS: Cardiac hemodynamics during stimulation of the right atrium, right ventricle and left ventricle in normal and abnormal hearts. Circulation 23: 933, 1966

15. Gilmore JP, Sarneff, SJ, Mitchell JH, Linden RJ: Synchronicity of ventricular contractions: 
observations comparing hemodynamic effects of atrial and ventricular pacing. Brit Heart $\mathrm{J}$ 25: 299, 1963

16. Ross J Jr, Linhart JW, Braunwald E: Effects of changing heart rate in man by electrostimulation of the right atrium. Studies at rest, during exercise and with isoproterenol. Circulation $23: 549,1965$

17. Parker JO, Khaya F, Case RB: Analysis of left ventricular function by atrial pacing. Circulation 43: 241, 1971

18. Sowton $\mathbf{E}$ : Hemodynamic studies in patients with artificial pacemakers. Brit Heart J 26: 737,1964

19. Delaye J, Gastro O, Pourchaire J, Gabades A, Genin A: Etude de la contractilite myocardique che le sujects porteurs d'atherome coronarien, au repos, sous stimulation auriculaire et sous perfusion d'angiotensine. Acta Cardiol 27: 197, 1972

20. Samet P, Castillo C, Bernstein WH, Fernandez P: Hemodynamic results of right atrial pacing in 33 normal subjects. Dis Chest 32: 652, 1967

21. Benchimol A, Duenas A, Ligget MS, Dimond EG: Contribution of atrial systole to the cardiac function at fixed and variable ventricular rate. Am J Cardiol 16: 11, 1967

22. Gesell RA: Auricular systole and its relation to ventricular output. Am J Physiol 29: 32, 1911-12

23. Greattinger JS, Carleton RA, Muenster JJ: Circulatory consequences in cardiac rhythm produced in patients by transthoracic direct current shock. J Clin Invest 43 : 2290, 1964

24. Masini V, Milazzotto F, Costantini A: Tempi sistolici nel blocco atrio-ventricolare completo prima e dopo stimolazione con segnapassi endocardico. Giorn It Cardiol 1: 459, 1971

25. Sonnenblick E, Morrow AG, Williams JF: Eflects of heart rate on dynamics of force development in the intact human ventricle. Circulation 23: 1945, 1966 